\title{
Na esteira da economia e da política: o espaço da cultura no Plano Nacional de Cultura - PNC.
}

Graciela Froehlich ${ }^{1}$

Resumo: O trabalho aqui proposto é resultado de análises preliminares de uma pesquisa ainda em andamento. O objetivo do trabalho é analisar a dimensão assumida pela cultura, na sua interface com os campos econômico e político, no Plano Nacional de Cultura (PNC). Este se constitui na base para a análise, pois se coloca como referência para as políticas públicas na área de cultura em nível de país. Procura-se trazer mais uma das formas com que o conceito de cultura é utilizado na atualidade, evidenciando a pluralidade de interpretações que esta noção assume, seus usos e apropriações diversas. Procura-se também analisar de que forma a cultura e o mercado estão imbricados e como políticas públicas que tomam por base o PNC podem vir a atuar nestas esferas. Para tanto, parte-se de uma abordagem do conteúdo deste documento, para então refletir com base na bibliografia disponível, as suas apropriações.

Palavras - chave: Cultura, Políticas Culturais, Plano Nacional de Cultura (PNC).

Abstract: The study proposed here is a result of preliminary analyses of ongoing research. The objective of the study is to analyze the dimension assumed by the culture in its interface with the economic and political fields in National Culture Plan (PNC). This Plan is the background for the analysis, because it stands as a reference for public policies in culture at the national level. It is searched for to bring more on the ways in which the concept of culture is used today, showing the plurality of interpretations that asssumes this notion, their various uses and appropriations. It intends to analyse the way the culture and market are interwoven and how public policies based on the PCN may come into play in these spheres. To do so, one starts with the approach of the content of this document, and then reflect on the basis of available literature, in its appropriations.

Keywords: Culture, Cultural Politics, National Culture Plan (PNC).

\footnotetext{
${ }^{1}$ Doutoranda em Antropologia, Universidade de Brasília. E-mail: gracielafr@gmail.com
}

Latitude, Vol. 4, n², pp. 09-24, 2010

DOI: https://doi.org/10.28998/2179-5428.20100202 
Na esteira da economia e da política: o espaço da cultura no Plano Nacional de Cultura-PNC.

\section{Introdução}

Vive-se um período em que novos desafios têm sido lançados ao trabalho dos pesquisadores em ciências sociais. A frase é recorrente, mas se adéqua à temática do trabalho proposto. Cada vez mais noções e conceitos das diferentes áreas do conhecimento das ciências sociais são utilizadas de diferentes formas, saindo do domínio exclusivo das disciplinas. É o caso do conceito de cultura, que nas políticas públicas de cultura assume uma dimensão diferenciada daquela com a qual habitualmente depara-se nos estudos acadêmicos, especialmente antropológicos. Tendo-se em vista essa questão, o presente trabalho tem como objetivo analisar a abordagem desta noção no Plano Nacional de Cultura (PNC).

A base para o trabalho que segue é, portanto, o Plano Nacional de Cultura, em sua segunda edição, do ano de 2008. Este se propõe a traçar as diretrizes para as políticas públicas na área da cultura no Brasil, servindo de referência para todas as iniciativas nesta área. O PNC nasce de um debate desenvolvido em nível nacional acerca da cultura e de formas de incentivo a atividades culturais por intermédio do poder público. Está previsto constitucionalmente desde a aprovação da emenda constitucional $n^{\mathrm{o}} 48$, do ano de 2005, que inseriu no artigo 215 a previsão de que o país teria um plano plurianual de cultura. As políticas públicas a serem realizadas com base neste documento, conforme nele apresentado, procuram incentivar as diversas manifestações culturais e identitárias existentes no Brasil, como forma de valorizar a diversidade nacional. O PNC apresenta um plano de ação que abrange noções de salvaguarda de bens simbólicos materiais e imateriais ${ }^{2}$, com vistas a assegurar o direito de acesso à cultura no país, em um projeto amplo e de longo prazo, aglutinando diversas iniciativas.

$\mathrm{O}$ PNC está organizado em quatro amplos capítulos. O primeiro faz uma introdução, apresentando a cultura, sua produção e fruição, como um direito a ser garantido pelo Estado a fim de promover a igualdade e a equidade. A cultura é apresentada sob três dimensões: simbólica, da cidadania e da economia. Ainda na introdução, o PNC é apresentado como a instância articuladora da política cultural brasileira, propondo uma gestão democrática das políticas culturais, cujas ações constituirão o Sistema Nacional de Cultura ${ }^{3}$. A valorização da diversidade cultural

\footnotetext{
${ }^{2}$ Conforme Oliven (2009) a distinção entre bens materiais e imateriais não é pacífica. O autor exemplifica a dificuldade em diferenciar essas duas noções da seguinte forma: "as propriedades químicas da água benta e da água comum são as mesmas; entretanto, a primeira água, ao contrário da segunda, tem um poder sagrado, que lhe foi conferido pela Igreja. Uma bandeira é um pedaço de tecido ao qual os habitantes de uma nação atribuem um significado igualmente sagrado. A comida é material, mas a culinária é imaterial" (Oliven, 2009, p.81-82).

${ }^{3} \mathrm{O}$ Sistema Nacional de Cultura é apresentado como um novo paradigma na gestão da cultura. Pretende promover de forma conjunta as políticas públicas, constituindo-se no mecanismo que dará efetividade ao Plano Nacional de Cultura.
} 
é também apresentada em âmbito internacional, onde o Plano é apresentado enquanto uma iniciativa que está em consonância com os debates internacionais no que diz respeito à cultura e sua promoção, como a ratificação pelo Congresso Nacional, em 2006, da "Convenção para a Proteção e a Promoção da Diversidade das Expressões Culturais". No segundo capítulo, estão descritas as diversas etapas de elaboração do PNC, sendo o debate público em sua construção posto em evidência. Sob o título "Valores e Conceitos", estão reunidas as ideias centrais que norteiam todo o PNC. O terceiro capítulo, intitulado "Diagnósticos e desafios para as políticas culturais", apresenta as linhas gerais de atuação nas políticas públicas, baseadas em dados estatísticos. E por fim, são apresentadas as propostas de diretrizes e ação de forma mais pontuada, com relação à criação de mecanismos e instituições de integração - como o Sistema Nacional de Cultura -, ao financiamento, à legislação, à criação, conservação, preservação e valorização do patrimônio artístico e cultural, ao estímulo à reflexão sobre as artes e a cultura, a valorização da diversidade, aos fluxos de produção e formação de público, aos equipamentos culturais e circulação da produção, o estímulo à difusão através da mídia, a capacitação e assistência ao trabalhador da cultura, o estímulo ao desenvolvimento da economia da cultura, o turismo cultural, a regulação econômica, a organização de instâncias consultivas e de participação direta e o diálogo com as iniciativas do setor privado e da sociedade civil.

Analisam-se no presente artigo as diferentes influências na construção de um conceito de cultura que torne viável o estabelecimento da política cultural. As dimensões simbólica, cidadã e econômica recebem enfoque especial, uma vez que é em torno destas que o Plano formula a sua concepção cultural. Ao lado destas questões propõem-se outras, como a separação entre cultura popular e cultura erudita e a trajetória das políticas culturais no Brasil, que serão abordadas de forma complementar.

\section{As iniciativas de incentivo à cultura no Brasil: breve exposição}

No Brasil, as políticas públicas na área cultural mostram concepções diversas no decorrer dos anos. Entre as primeiras iniciativas estão aquelas que correspondem à salvaguarda do patrimônio histórico e artístico. Tendo em vista essa questão, apresento a seguir uma breve exposição da trajetória dessas políticas públicas, perpassando pelas diferentes abordagens das mesmas. A questão da salvaguarda dos bens culturais brasileiros não é novidade da Constituição de 1988; esta temática já está presente desde os primeiros anos da década de 1930. Assim sendo, o PNC se inscreve em uma tradição de políticas culturais no Brasil, não se podendo colocá-lo como dissociado dessas iniciativas precedentes. As constituições de 1934 e 1937 abordam principalmente a preservação do patrimônio material brasileiro, mas a Carta de 1937 traz uma importante contribuição, uma vez que submeteu o instituto da propriedade privada ao interesse do Estado. Em 1936 é criado o então chamado Serviço do Patrimônio Histórico e Artístico Nacional, o Sphan. Suas ações de preservação voltavam-se primordialmente aos bens de natureza material - pedra e cal -, sendo as propostas dos intelectuais vinculados a 
Na esteira da economia e da política: o espaço da cultura no Plano Nacional de Cultura-PNC.

ele "orientadas por critérios seletivos pautados pela identificação da característica estética das obras, sua autenticidade e seu caráter excepcional" (Funari, 2006, p.45).

Os bens culturais assim compreendidos excluíam os bens não pertencentes às elites, que acabaram relegados ao esquecimento. Durante a era Vargas, a seleção do patrimônio a ser preservado era feita em função dos vínculos com a história oficial da nação, seleção esta, que incluía edifícios do período colonial e palácios governamentais. No período militar, percebem-se profundas alterações na relação entre o Estado e os produtores culturais, principalmente com a decretação do Ato Institucional no5 (AI-5), onde a censura do governo era dominante. No governo de Médici, a partir de 1969, foi criado o Programa de Ação Cultural (PAC), com o objetivo de fomentar o crédito e o financiamento de ações voltadas à cultura. Somente sessenta anos depois da criação do Sphan, hoje Iphan - Instituto do Patrimônio Histórico e Artístico Nacional -, é que foi instituído o registro de bens culturais de natureza imaterial, através do Decreto 3.551 do ano de 2000. Para Funari, "as políticas públicas devotadas à proteção patrimonial têm cambiado de acordo com os conceitos de identidade nacional dos governos que se sucedem no poder" (ibid, p.47).

O primeiro plano oficial na área de cultura foi implantado em 1975, sendo denominado "Política Nacional de Cultura". Conforme Ianni, "durante a ditadura militar, o Estado foi colocado no centro da produção cultural do país" (1991, p.174). A organização da produção cultural dirigida pela "Política Nacional de Cultura", parte do reconhecimento por parte do Estado da necessidade de "criar tradição e memória", consolidando a "identidade nacional" (Branco, 1977 apud Ianni, 1991, p.175). Para Ianni, "o Estado foi levado a desenvolver uma vasta e complexa organização cultural, que permeia o conjunto da sociedade civil, em suas instituições ou grupos e classes sociais" (Ianni, 1991, p. 177). As atividades artesanais e folclóricas entram em cena como "símbolos culturais da nossa história", buscando a criação de uma identidade e cultura nacionais. O folclore é utilizado, neste contexto, com vistas a criar um espetáculo para o divertimento, especialmente no que tange aos aspectos da sociedade escravista (ibid). O que se procura através desta política, é a criação de uma narrativa da nação, construindose os parâmetros daquilo que pode receber o adjetivo de brasileiro, demarcador de uma identidade nacional específica. Nessa política, Miceli (1984) identifica uma posição de proteção dos valores culturais nacionais, frente à imposição de traços culturais estrangeiros. Procura-se assim, a construção de uma identidade e cultura "genuinamente brasileiras". O autor percebe também nesta política uma divisão entre a chamada cultura legítima, compreendendo o "patrimônio histórico e artístico", e um "patrimônio menor", diversificado, produzido pelas camadas populares, que constituiria o folclore.

Em 1979, foi criada a Fundação Nacional Pró-Memória, com o objetivo de diminuir a burocracia e agilizar a captação de recursos para os projetos culturais. Nesse período, conforme Funari (2006), a concepção de patrimônio, e conseqüentemente da cultura, foi alargada, em razão do reconhecimento de bens procedentes do saber popular, proporcionando uma compreensão do patrimônio baseada na diversidade cultural, étnica e religiosa do país. Durante os anos de 1980, a noção de bens a serem preservados tomou novo impulso com as políticas 
de incentivo fiscal voltadas para a cultura, como é o caso da Lei Sarney, de 1986. Segundo Funari (2006), ao mesmo tempo em que esta lei favoreceu a proteção do patrimônio, propiciou o desenvolvimento desenfreado do marketing cultural, consolidado na década seguinte.

Rubim afirma que "somente nos períodos autoritários o Brasil conheceu políticas culturais mais sistemáticas, nas quais o Estado assumiu um papel mais ativo e, por conseguinte, eclipsou a tradição de ausência" (Rubim, 2008, p. 187). Assim como na ditadura, através do PNC, o Estado incumbe-se da tarefa de fomentar e regular as expressões simbólicas. No entanto, pela reiteração da busca de canais de diálogo com a população acerca dos valores do Plano e das ações a serem implementadas através dele, o PNC reveste-se de um caráter democrático que o coloca como uma iniciativa inovadora na esfera das políticas culturais. Seu próprio processo de construção, na medida em que estabelece um amplo debate em nível nacional, por meio de reuniões e conferências ${ }^{4}$, constitui uma iniciativa diferenciada, colocando a participação dos interessados em sua construção. Conforme Rubim (2008), o processo de construção do PNC deu-se como uma verdadeira política pública, pois foi submetido ao debate público, que incorpora a participação da sociedade na elaboração das políticas. No entanto, salienta que o formato organizacional escolhido para as reuniões e seminários conduziu a uma discussão fragmentada e até empobrecida do Plano (Rubim, 2008b).

Percebe-se assim uma certa continuidade com algumas das propostas destas políticas precedentes. Se teoricamente as iniciativas de salvaguarda do patrimônio buscam também dar voz a grupos minoritários, é preciso pensar em que medida, efetivamente, tal proteção está se dando. Ainda que as iniciativas propostas pelo PNC não se encontram em fase de implementação ${ }^{5}$, cabe uma vigilância em relação a tais aspectos. A espetacularização da cultura, conforme apontado por Ianni (1991) na questão da sociedade escravista, é também uma via de mão dupla. Ao mesmo tempo em que pode trazer benefícios econômicos, pode também divulgar mensagens acríticas de um período de tamanha exploração na sociedade brasileira.

\section{As dimensões da cultura conforme o PNC: simbólica, cidadã e econômica}

Considerando assim a importância deste documento enquanto base para uma política cultural bastante ampla, procuro neste trabalho analisar a interrelação presente nele entre a cultura, a economia e a política. Estes três aspectos estão contemplados no Plano quando este apresenta a cultura sob três dimensões: simbólica, cidadã e econômica.

As três dimensões são fundamentais, pois na sua inter-relação busca-se construir um conceito de cultura que satisfaça as necessidades da política pública. Trata-se de operacionalizar institucionalmente a questão cultural, com vistas a

\footnotetext{
${ }^{4}$ À trajetória de formulação do PNC é dedicado um capítulo do documento. O diálogo com a sociedade se deu por intermédio de diversos encontros, dentre os quais se podem citar o Seminário Nacional Cultura para Todos (2003) e a Conferência Nacional de Cultura (2005).

${ }^{5}$ No momento, o Plano Nacional de Cultura encontra-se em tramitação no Senado Federal, onde foi aprovado pela Comissão de Assuntos Econômicos em 7 de julho deste ano.
} 
Na esteira da economia e da política: o espaço da cultura no Plano Nacional de Cultura-PNC.

legitimar a atuação do Estado, bem como apresentar uma ferramenta que permita a viabilização das iniciativas propostas pelo Plano.

Em primeiro lugar, é conferido destaque à concepção antropológica de cultura. Ela ocupa o centro da dimensão denominada "simbólica", propondo-se a "'cultivar' as infinitas possibilidades de criação simbólica expressas em modos de vida, motivações, crenças religiosas, valores, práticas, rituais e identidades" (Ministério da Cultura e Câmara Federal, 2008, p.11). Aqui há uma preocupação com o estímulo à diversidade da cultura brasileira, prevendo a atuação do poder público nos diferentes ambientes e dimensões em que ela se manifesta. Outro aspecto destacado nessa dimensão é a busca, através das iniciativas colocadas pelo PNC, de geração laços de autoestima e identidade entre os brasileiros.

A diversidade parece assumir nesse contexto um papel paradoxal: é tomada como um elemento diferenciador em relação ao exterior - "maior patrimônio da população brasileira" - e unificador internamente, uma vez que esse capital simbólico, diverso, deve proporcionar a criação de laços de identidade entre os brasileiros, aproximando o diferente. A valorização da diversidade também surge como um mecanismo protetor em relação ao receio dos processos de hegemonização cultural engendrados pela globalização. Tal aspecto é explicitado no Plano:

na atualidade, como reação a esse processo de homogeneização cultural induzida em âmbito local e mundial, surgem iniciativas voltadas para a proteção e afirmação da diversidade cultural da humanidade. Tal perspectiva pressupõe maior responsabilidade do Estado na valorização do patrimônio material e imaterial de cada nação (ibid, p. 30).

Proteger e estimular a diversidade tornam-se então metas para o Estado, no sentido de evitar as consequências danosas da globalização, especialmente aquelas que afetam a expressão simbólica dos diferentes grupos.

A diversidade é tomada também como condição para o exercício da cidadania: "assegurar o pluralismo da expressão identitária é dever do poder público, tendo em vista a importância da valorização e proteção da diversidade para o exercício democrático da cidadania" (ibid, p. 41-42). Esta concepção insere-se em uma moderna tradição, onde os direitos a serem garantidos pelo Estado não se referem apenas aos indivíduos tomados isoladamente, mas aos grupos em que estão inseridos. No momento de introdução na ONU, do Programa das Nações Unidas para os Povos Indígenas, o então Secretário Geral das Nações Unidas, Boutros-Ghali fez uma afirmação que corrobora este reconhecimento:

dessa forma, nós nos damos conta de que os direitos humanos abarcam não apenas os direitos individuais, mas também os direitos coletivos, os direitos históricos. Nós estamos descobrindo os 'novos direitos humanos', que incluem, em primeiro lugar e 
fundamentalmente, direitos culturais... Podemos até mesmo afirmar que não pode haver direitos humanos se não for preservada a autenticidade cultural (BoutrosGhali, 1994, apud Kuper: 2002, p.217).

A noção de cultura apresentada no PNC liga-se diretamente ao discurso da UNESCO sobre a temática. Nas declarações, recomendações e convenções encontra-se uma base que orienta o discurso do Plano, demonstrando uma articulação global/local. Conforme Alves, a "UNESCO passou a capitanear as discussões realizadas em âmbito mundial no que diz respeito a um conjunto de ações e propostas de regulamentação, definição e normatização da categoria cultura em face das profundas transformações ocorridas no final do século XX" (2009, p.173 grifos do autor). O autor mostra também que nesse processo o Brasil ocupou papel de destaque, especialmente na aprovação da Convenção Sobre a Proteção e Promoção da Diversidade das Expressões Culturais, em 2005, que passou a se chamar desta forma por sugestão do Brasil. Esta articulação do Brasil em relação ao cenário internacional é evidenciada pelo Plano ao dedicar um item em que procura demonstrar de que forma o Brasil está engajado nas iniciativas internacionais de promoção dos direitos culturais. Nele, o PNC destaca o papel desempenhado pelo Brasil na aprovação e implementação de acordos e tratados internacionais, como a Agenda 21 da Cultura e a Convenção para a Proteção e a Promoção da Diversidade das Expressões Culturais.

A adoção de uma perspectiva antropológica de cultura pelo PNC procura trazer para as iniciativas governamentais aspectos que nas políticas anteriores não se encontravam presentes. No entanto, essa abordagem requer uma análise cuidadosa. Se considerarmos cultura para a antropologia, de forma bastante resumida, como a ordenação do mundo através de símbolos e significados, essa abordagem torna-se ainda mais difícil. Para Chauí (2006), uma concepção antropológica abrangente de cultura, impossibilita, de fato e de direito, que o Estado produza cultura. Isto porque dessa forma, como afirma Chauí:

o Estado passa a ser visto, ele próprio, como um dos elementos integrantes da cultura, isto é, como uma das maneiras pelas quais, em condições históricas determinadas e sob os imperativos da divisão social das classes, uma sociedade cria para si própria os símbolos, os signos e as imagens do poder. É produto da cultura e não produtor de cultura (2006, p. 135).

Para a implantação de políticas culturais faz-se necessário, no entanto, que o Estado se coloque, senão como produtor, pelo menos como fomentador da cultura. $\mathrm{Na}$ medida em que busca organizar a produção cultural, participa ao mesmo tempo dos processos culturais. Pode-se dizer assim, que ao mesmo tempo em que alimenta a cultura, é alimentado por ela. 
Na esteira da economia e da política: o espaço da cultura no Plano Nacional de Cultura-PNC.

No entanto, a autora defende um alargamento da perspectiva adotada historicamente pelo Estado, que privilegiava as Belas Artes em detrimento da produção cultural como um todo. Este é também o posicionamento inicial do PNC:

considerando-se que a diversidade cultural é o maior patrimônio da população brasileira, no âmbito do PNC busca-se transcender as linguagens artísticas, sem, contudo minimizar sua importância. Uma perspectiva ampliada, que articula as diversas dimensões da cultura, ganhou corpo e espaço na estrutura de financiamento público nos últimos anos e é um dos pilares do Plano Nacional de Cultura (Ministério da Cultura e Câmara Federal, 2008, p.12).

Apesar de apresentar a pretensão de uma concepção antropológica abrangente de cultura, é preciso levar em consideração em que medida o Plano foca suas propostas de atuação nos aspectos preponderantemente midiáticos e artísticos da cultura ${ }^{6}$ que, apesar de estarem presentes em uma perspectiva antropológica, não a considera somente sob estes aspectos.

Conforme afirmado no PNC, "não cabe aos governos ou às empresas conduzir a produção da cultura, seja ela erudita ou popular, impondo-lhe hierarquias e sistemas de valores" (ibid, p.31 grifos meus). Porém, no reconhecimento destas classes - erudito e popular - uma hierarquia já está implícita, seguindo os valores da sociedade ocidental capitalista ${ }^{7}$. Sob a ótica dos estudos culturais - cuja criação remonta à década de 1960, na Inglaterra - a alta cultura atua como um sinal de status, que reforça o poder da classe dominante, ao mesmo tempo em que mantém sua opressão sobre a maioria (Kuper, 2002). Por outro lado, a cultura popular é vista por eles com bons olhos, uma vez que possui um caráter de resistência frente às investidas da classe dirigente. Para Kuper, "quando a cultura é restringida às artes, à mídia e ao sistema educacional, ela lida apenas com alguns aspectos do que os antropólogos entendem por cultura" (ibid, p. 293). Vê-se assim, que na operacionalização de políticas públicas para a cultura, como o PNC, a abordagem antropológica apontada no início do documento fica prejudicada no decorrer do texto, que invoca a dicotomia erudito/popular tão problematizada nos estudos dessa disciplina.

Os produtos finais resultantes das atividades erudita e popular são também vistos de forma diferenciada. Enquanto a cultura popular produziria artesanato e folclore, o resultado da produção erudita é artístico. Canclini (2008) procura

\footnotetext{
${ }^{6}$ Conforme Neves (2008), esta lógica é hegemônica nas sociedades ocidentais, que separa manifestações artístico-culturais das manifestações mais cotidianas.

${ }^{7}$ Seguindo a tendência dos estudos da Escola de Frankfurt, Leo Lowenthal (1975) opõe também o conceito de arte ao de cultura popular. Para este autor, "atualmente, as produções artísticas vêm perdendo cada vez mais o caráter de espontaneidade e vêm sendo substituídas pelos fenômenos da cultura popular, os quais nada mais são do que a reprodução manipulada da realidade tal como ela é" (Lowenthal, 1975, p.301).
} 
analisar as concepções de arte e artesanato, e a forma com que estas noções se encontram na modernidade. Para ele, o popular, onde se encontra o artesanato, é visto como o "pré-moderno, subsidiário", trabalhado de forma pré-industrial. Enquanto consumidores, os populares seriam meros receptáculos e reprodutores da ideologia dominante. A arte, por sua vez, é entendida como um movimento desinteressado, autônomo, onde o belo predomina sobre a utilidade, correspondendo aos interesses e gostos da burguesia. $\mathrm{O}$ artesanato, nesse sentido, não poderia dissociar-se da finalidade prática que possui para indígenas e camponeses que os produzem. O que o autor demonstra é que tanto a arte quanto o artesanato encontram-se atravessados pelos processos da modernidade. "Como o artístico e o artesanal estão incluídos em processos massivos de circulação das mensagens, suas fontes de aproveitamento de imagens e formas, seus canais de difusão e seus públicos costumam coincidir" (Canclini, 2008, p. 245).

Essa diferenciação entre erudito e popular também está presente no item "Diagnósticos e desafios para as políticas culturais". Neste, é realizada uma separação entre "linguagens artísticas" e "manifestações culturais". O primeiro engloba as seguintes iniciativas: proporcionar a capacitação e a profissionalização dos trabalhadores culturais como política estratégica para as linguagens e a experiência estética; ampliar o reconhecimento da multiplicidade das artes e dos artistas visuais; tornar o Brasil um grande produtor e exportador de audiovisual; estimular a valorização dos repertórios tradicionais e das novas modalidades circenses; valorizar e estimular a circulação das diversas práticas de dança; ampliar o acesso à produção de obras literárias; tornar a música popular brasileira um elemento dinamizador da cidadania e da economia; estabelecer uma política nacional de formação profissional, pesquisa, registro e difusão da música de concerto; ampliar o público e valorizar a inovação e a diversidade da produção teatral brasileira. Sob a rubrica de manifestações culturais, inscrevem-se as seguintes: fortalecer o uso do português e valorizar as línguas indígenas; reconhecer e promover as condições de produção e fruição das culturas Populares; promover a culinária como registro e expressão da diversidade brasileira; estimular a produção de design, moda e vestuário como meios de expressão da diversidade e dinamização estratégica da economia. Nessa separação realizada no Plano, merece destaque a inclusão de modalidades circenses enquanto parte das linguagens artísticas, assim como a música popular brasileira e diferentes modalidades de dança. No entanto, é sob este título que se encontram reunidas as expressões clássicas das Belas Artes: pintura, música de concerto e obras literárias. Assim sendo, permanece, ainda que de forma diferenciada, a dicotomia erudito/popular.

Esta separação parece estar mais próxima da concepção iluminista de civilização, que da noção antropológica de cultura. DaMatta (2000) enfatiza que "no mundo da civilização, nós estamos no terreno do mais ou menos. Nele, podese afirmar que uma pessoa é mais ou menos civilizada do que outra. Mas no mundo da cultura, que tem como objetivo não a pessoa "culta", mas o domínio do "cultural" todos temos cultura" (DaMatta, 2000, p. 57-8). A reiteração da separação entre erudito e popular evoca a concepção de civilização em detrimento da cultura. Ao buscar pela formação de leitores, de um público para o teatro e cinema, para 
Na esteira da economia e da política: o espaço da cultura no Plano Nacional de Cultura - PNC.

exposições e museus, coloca-se a busca pela entrada em um mundo civilizado, mais que cultural, ou, pelo menos, em um universo em que ambas as denominações são tomadas como sinônimos. No entanto, busca-se uma participação naqueles instrumentos e códigos historicamente produzidos pela elite dominante.

O acesso à cultura é abordado também na dimensão cidadã, onde é apresentado como um direito a ser promovido

por meio do estímulo à criação artística, democratização das condições de produção, oferta de formação, expansão dos meios de difusão, ampliação das possibilidades de fruição, intensificação das capacidades de preservação do patrimônio e estabelecimento da livre circulação de valores culturais, respeitando-se os direitos autorais e conexos e os direitos de acesso e levando-se em conta os novos meios e modelos de difusão e fruição cultural (Ministério da Cultura e Câmara Federal, 2008, p.11).

Aqui a cultura é entendida enquanto um direito que justifica a ação do Estado por meio de políticas públicas. A preocupação inicial é, conforme o texto, com a desigualdade no acesso a bens e equipamentos culturais, como teatros, museus e cinemas.

Conforme Neves (2008), ao definir-se o acesso aos bens culturais como um direito a ser garantido pelo Estado, este acesso remonta a ideia de Belas Artes, no sentido de alta cultura, conforme colocado anteriormente. Essa oposição vai de encontro às proposições da antropologia, que vem incessantemente defendendo um posicionamento de não hierarquização entre as culturas. Assim o autor afirma que "a questão do acesso diz respeito a tipos de cultura diferentes e ao privilégio dado a um tipo de cultura, tanto numa hierarquização, em certa medida mundial, quanto numa hierarquização nacional" (Neves, 2008, p.100). Lévi-Strauss, em Raça e Cultura, já apontava para a necessidade de analisar as diferenças entre os grupos não de acordo com uma única escala, pois os valores variam de cultura para cultura.

A dimensão econômica visa regular as "economias da cultura" com vistas a "evitar os monopólios comerciais, a exclusão e os impactos destrutivos da exploração predatória do meio ambiente e dos valores simbólicos a ele relacionados" (Ministério da Cultura e Câmara Federal, 2008, p.12). O incentivo à cultura é tomado como um dos vetores do desenvolvimento econômico, que por sua vez deve ser justo e sustentável. A cultura é vista também como fonte de geração de ocupação e renda, devendo ser promovida pelos meios ao alcance do Estado. É colocada também uma preocupação com o mercado enquanto meio regulador das dinâmicas de expressão simbólica, o que, de certa forma, legitima a interferência estatal.

De acordo com Canclini: 
a incorporação dos bens folclóricos a circuitos comerciais, que costuma ser analisada como se seus únicos efeitos fossem homogeneizar os formatos e dissolver as características locais, mostra que a expansão do mercado necessita ocupar-se também dos setores que resistem ao consumo uniforme ou encontram dificuldades para participar dele. (...) Através das diversas motivações de cada setor - afirmar sua identidade, marcar uma definição política nacional popular ou a distinção de um gosto refinado com enraizamento tradicional - essa ampliação do mercado contribui para expandir o folclore (2008, pp. 216-217).

No que tange aos aspectos folclóricos, Canclini (2008) evidencia que seu crescimento dá-se em virtude do incremento proporcionado pelo Estado. Segundo ele, os objetivos são diversos, como a criação de empregos, o fortalecimento do turismo, exportação de bens tradicionais, entre outros. Estes são também alguns dos objetivos brasileiros com as iniciativas a serem implementados através do $\mathrm{PNC}^{8}$.

$\mathrm{Na}$ dimensão econômica, a noção de cultura é interpenetrada pela perspectiva do desenvolvimento. A cultura foi apontada durante muito tempo como um entrave ao desenvolvimento do país. Pensada desta forma, a cultura é tomada como um definidor negativo, evocando o jeitinho brasileiro, as praias e as festas (DaMatta, 2000). Porém, ao ser vista desta forma, a cultura é usada conforme um modelo rígido e elementar, em que a totalidade dos meios simbólicos é reduzida a alguns traços definidores que são comparadas a culturas ou sistemas vistas como superiores e mais avançadas (ibid). No entanto, ao adotar-se uma perspectiva antropológica mais moderna - no sentido de ordenamento da experiência humana por meios simbólicos - "a cultura deixa de ser um obstáculo para ser compreendida na sua dinâmica e na sua positividade" (ibid, p. 57). O PNC assim, ao pretender uma abordagem antropológica, busca captar os aspectos positivos da cultura, das diferentes culturas existentes no país, de modo a transformá-la em mais um elemento de desenvolvimento, e não um obstáculo ao mesmo. Isto tudo, tendo-se em vista as dificuldades já apontadas acima na adoção de uma concepção antropológica de cultura.

A ideia de sociedade civil, aliada ao desenvolvimento, conforme DaMatta, se insere em um vocabulário positivo, universal e dominante. Na sociedade civil, pressupõe-se um terreno de pura racionalidade - ocidental e capitalista, de um cálculo bem definido entre fins e meios. Essa concepção evocada pelo Estado na

${ }^{8}$ De modo geral, o PNC resume da seguinte forma as iniciativas de inclusão e desenvolvimento: “formação profissional; a regulamentação do mercado de trabalho para as categorias envolvidas com a produção cultural; e o estímulo aos investimentos e ao empreendedorismo nas atividades econômicas de base cultural, entre elas o turismo, as comunicações, a indústria gráfica, a fonográfica, a arquitetura, a moda dentre outras" (Ministério da Cultura e Câmara Federal, 2008, p.87). 
Na esteira da economia e da política: o espaço da cultura no Plano Nacional de Cultura - PNC.

formulação de suas políticas é muitas vezes incompatível com as visões de mundo de muitos grupos que integram a diversidade nacional, tão enfaticamente defendida pelo PNC. Ao trabalhar conforme esta ótica, estão sendo desconsideradas outras formas de organização da atividade social, uma vez que a noção de sociedade civil está na base da formulação de todas as iniciativas propostas pelo Plano. O que à primeira vista parece ser uma forma democrática de lidar com a diversidade, concentra uma visão que não dá conta das diferentes dinâmicas de organização social, uma vez que se baseia numa concepção específica de sociedade - ocidental, "civilizada" e moderna, onde o cálculo racional entre meios e fins é predominante.

A relação entre cultura e desenvolvimento é também abordada pela Política Nacional de Cultura, da ditadura militar, ao considerar que "o desenvolvimento não é um fato de natureza puramente econômica. Ao contrário, possui uma dimensão cultural que, não respeitada, compromete o conjunto" (Política Nacional de Cultura, apud Ianni, 1991, p. 175). Sendo assim, esta política reconhece a existência de aspectos culturais que se tornam aliados à sua política de desenvolvimento. Devido a isso, torna-se imperativo incentivar a produção, circulação e o consumo de folclore, patrimônios - científico e histórico -, cinema, teatro, dança, música, entre outros. Da mesma forma, o Plano Nacional de Cultura estabelece uma relação entre cultura e desenvolvimento, onde a primeira deixa de ser um obstáculo, e passa a ser considerada um vetor para o segundo.

Ianni (1991) afirma ainda, que, no contexto da ditadura militar, o Estado transformou-se em uma poderosa indústria cultural, centralizando e controlando a produção cultural, de acordo com os interesses das classes dominantes. $\mathrm{O}$ autor percebe uma clara distinção entre o patrimônio da classe dominante e aquele pertencente às classes subalternas: o primeiro é "histórico e científico", enquanto o segundo é "artesanal e folclórico".

Miceli (1984) aponta para uma tendência previdenciária no subsídio estatal para a cultura nos anos 1970. O Estado toma para si a incumbência de financiar as atividades culturais tendo em vista a incapacidade do setor privado em realizar tal tarefa. No entanto, não são todas as esferas pelas quais ele se torna responsável. À iniciativa privada permanece o setor com maiores retornos financeiros, como a televisão. Já o poder público responsabiliza-se pelas tarefas de conservação e proteção do patrimônio histórico e artístico. Há no PNC uma tendência semelhante, na medida em que direciona grande parte de suas iniciativas para a valorização do patrimônio, com ênfase na diversidade cultural. Ele traz, no entanto, uma preocupação com o fortalecimento da televisão pública, com a inovação científica e tecnológica, tomada como um "valor estratégico para a cultura", e também com o turismo. A participação do Estado nestes campos sugere uma mudança nessa tendência previdenciária, tendo em vista seu envolvimento em dinâmicas mais lucrativas, e conferidas, primordialmente, ao setor privado.

No contexto da economia da cultura existe uma preocupação iminente com a mercantilização, denunciada principalmente pelos estudos da indústria cultural. Conforme Adorno e Horkheimer (1985), são características da cultura contemporânea a semelhança e a padronização; o foco de suas análises são os meios de comunicação de massa, como o cinema, o rádio, a televisão, as revistas. 
Os produtos culturais são assim fabricados, no mesmo sentido da produção técnica fabril, em que os valores orçamentários "nada têm a ver com os valores objetivos, com o sentido dos produtos" (Adorno e Horkheimer, 1985, p. 116). A mesma preocupação pode ser vista em Ianni (1991):

a mercantilização da cultura vai longe, espalha-se pelo mercado, pouco sabe de fronteiras. Nesse processo, o capitalismo introduz também a obra de arte no mercado. Ela passa a competir com as outras mercadorias e as demais obras de arte. Aos poucos, isso altera as condições de trabalho e criação do artista, escritor e outros (Ianni, 1991, p. 192).

Trata-se assim de uma preocupação com uma "invasão" de valores capitalistas e consumistas em um terreno que parece apresentar-se como o reino da pureza de valores e do caráter genuíno da criação artística. Uma vez imersos nesse processo de mercantilização, os criadores estariam fadados a uma produção com vistas ao mercado, onde a autenticidade de sua criatividade e do próprio processo criador encontrar-se-iam marejados pela influência nefasta dos critérios capitalistas.

Para Canclini (2008b) a globalização e, por extensão, o modo de produção capitalista, afeta de forma diferente as diversas nações, e também os diferentes setores dentro de cada uma delas. Em função disso, ela não deve ser, para ele, analisada somente tendo-se em vista um processo de homogeneização, pois muitas diferenças resistem às investidas da globalização.

Em relação à noção de patrimônio, a análise segue um percurso semelhante. Tamaso (2005) identifica que este é quase sempre acionado pelas elites, onde os valores econômicos e políticos exercem papel preponderante em relação às representações sociais dos mesmos. Ela identifica que, em muitos casos, o reconhecimento patrimonial levou a um processo de gentrification, que transformou os espaços em alvos de investimento público e privado (Tamaso, 2005, p. 14). O ponto negativo desta prática está em deslocar as populações que habitam estes locais em nome de um desenvolvimento econômico que desconsidera o elemento humano enquanto formador deste desenvolvimento. É o que ocorre em muitas áreas em que ocorrem desapropriações com vistas a atribuir novos usos aos espaços, como bares e restaurantes, onde, em razão das condições econômicas da população, acabam excluídas desses ambientes.

Para Chauí, a ação estatal que adota a lógica da indústria cultural e do mercado cultural, traz um "tratamento moderno da cultura", apresentando-se como um "balcão para atendimento de demandas" (Chauí, 2006, p.135). Esse campo, por suas características peculiares, não pode ser regulado pela ótica mercadológica, segundo a autora, pois a lógica do consumo e da moda, bem como da transformação da cultura em mero artefato de entretenimento são incompatíveis com o caráter criador e crítico das culturas. A instrumentalização do lazer e do lúdico, presentes em determinados arranjos culturais, pode acarretar a uma redução dos mesmos a representações supérfluas cujos sentidos 
Na esteira da economia e da política: o espaço da cultura no Plano Nacional de Cultura - PNC.

comercializados estão muito distantes daqueles que orientaram a criação dos produtos (Chauí, 2006).

O indivíduo, no contexto das políticas públicas é atravessado por diferentes concepções, que servem como eixos de sustentação das dimensões em que a cultura é apresentada. Ele é ao mesmo tempo cidadão, membro da sociedade civil e público-alvo; é também sujeito e agente, sem deixar de ser produtor e consumidor. Nas políticas culturais, os grupos passam também a ser inseridos neste esquema, como sujeitos de direito, agentes e produtores/consumidores de riqueza. Torna-se necessária então, uma articulação entre essas posições assumidas no sentido de promover um desenvolvimento que valorize a criação simbólica em seus próprios termos, segundo valores que lhes são próprios.

\section{Considerações Finais}

Por tudo isso, percebe-se no Plano Nacional de Cultura uma tentativa de construir um conceito de cultura próprio, com vistas a operacionalizar uma política pública de larga escala. Percebe-se nele, uma diferenciação entre cultura erudita e popular que permeia as iniciativas propostas, apesar de propor uma abordagem antropológica, que não compartilha dessa dicotomia. Ao conceber o acesso à cultura como um direito, é à cultura erudita que está se buscando.

O Estado se coloca na posição de regulador das economias de cultura, com vistas a assegurar os direitos culturais. Assim como na Política Nacional de Cultura, de 1975, ele procura assumir o centro da produção cultural, muito pela vasta abrangência de suas propostas. Na busca pelo desenvolvimento, a cultura torna-se mais um dos aspectos a entrar em cena.

De acordo com Sahlins (1997), referindo-se à apropriação de signos ocidentais por grupos indígenas, "temos razões para ser céticos, portanto, diante de noções simplistas de "aculturação", concebida como uma conseqüência funcional necessária do envolvimento na economia de mercado" (Sahlins, 1997, p.64). Sua proposta é a de se testemunhar a cultura nesse processo, não apenas assumir posturas de denúncia em relação à hegemonia. Entendo assim que as políticas culturais, entre elas o PNC, precisam ser analisadas de forma a aliar intencionalidade dos agentes de promoção e implementação das mesmas, por um lado, e reconstrução de significados por outro.

Conforme Agier "a identidade cultural tornou-se um lugar comum das novas formas de político, fonte de mobilização popular em zonas rurais e urbanas (...)"(2001, p.21). A compreensão da cultura e consequentemente da identidade como vetores de desenvolvimento vai ao encontro da afirmativa de Agier: "o espetáculo da diferença cultural se torna não somente um objeto identitário, mas também um recurso político ou econômico para indivíduos e redes à procura de um lugar na modernidade" (ibid, p.22). A dimensão econômica, trazida pelo Plano, procura justamente enfatizar a capacidade de as expressões simbólicas atuarem como mecanismos geradores de renda desenvolvimento. É válido salientar, que ao abordar o assunto do desenvolvimento, este sempre vem acompanhado do adjetivo "sustentável", atribuindo um caráter diferenciado, qualitativo, a este 
desenvolvimento ${ }^{9}$. O Estado atuaria neste contexto no sentido de evitar o descontrole proporcionado pelo livre mercado, seus impactos predatórios sobre o ambiente e os valores simbólicos.

As dimensões apresentadas pelo PNC encontram-se entrelaçadas, apresentando a cultura na sua diversidade, enquanto um direito a ser garantido pelo Estado, e incentivado, por ser tomado como um vetor para o desenvolvimento. O desafio que se impõe é o de como dar forma, como incentivar economicamente aspectos imateriais do simbólico. Os aspectos materiais parecem à primeira vista serem de mais fácil apreensão e, por conseguinte sem maiores dificuldades no que diz respeito à sua efetivação por meio de políticas públicas. Porém, é preciso levar em consideração o percurso de um artefato, por exemplo, que possui um sentido determinado para determinado grupo, mas que ao ser exposto para outros grupos, dotados de outros valores, passa a assumir significados diversos. Nesse trajeto, é preciso levar em consideração a ação da economia da cultura, pensar em que medida esta participa da construção de um artefato novo. O que está em jogo aqui não é a descaracterização de uma determinada cultura pela ação do mercado, mas a sua influência nas representações dos diferentes grupos. Além disso, a influência do Estado, atuando nessa economia da cultura também necessita ser pensada, uma vez que estabelece propostas e cria regras para o incentivo à cultura, participando dos processos culturais. Faz-se necessária também, uma reflexão acerca da permanência da dicotomia erudito/popular, de forma a trabalhar a cultura como totalidade diferenciada não hierárquica.

\section{Bibliográfias}

ADORNO, Theodor e HORKHEIMER. A indústria cultural: o esclarecimento como mistificação das massas In: Dialética do Esclarecimento. Rio de Janeiro: Jorge Zahar Editor, 1985.

AGIER, Michel. Distúrbios identitários em tempos de globalização. Revista Mana. Rio de Janeiro, 2001. pp.7-33.

ALVES, Elder Patrick Maia. A economia simbólica da cultura popular sertanejonordestina. Tese de Doutorado defendida no Programa de Pós-Graduação em Sociologia PPG-Sol Unb, 2009.

CANCLINI, Néstor, García. Culturas Híbridas. 4. ed. São Paulo: Edusp, 2008.

CANCLINI, Néstor García. Consumidores e Cidadãos. 7.ed. Rio de Janeiro: Editora UFRJ, 2008b.

CHAUÍ, Marilena. Cidadania cultural. O direito à cultura. São Paulo: Editora Fundação Perseu Abramo, 2006.

${ }^{9}$ Conforme Oosterbeek e Scheunemann (2010), a expressão "desenvolvimento sustentável" encerra uma redundância, pois para ser considerado desenvolvimento deve ser, obrigatoriamente, sustentável, caso contrário, significa crescimento. 
Na esteira da economia e da política: o espaço da cultura no Plano Nacional de Cultura-PNC.

DAMATTA, Roberto. Sociedade civil, desenvolvimento e cultura. IN: Cultura e Desenvolvimento. Cadernos do nosso tempo. Rio de Janeiro: Edições Fundo Nacional de Cultura, 2000.

FUNARI, Pedro Paulo Abreu e PELEGRINI, Sandra de Cássia Araújo. Patrimônio histórico e cultural. Rio de Janeiro: Jorge Zahar, 2006.

IANNI, Octavio. Ensaios de Sociologia da Cultura. Rio de Janeiro: Editora Civilização Brasileira, 1991.

LOWENTHAL, Leo. Perspectivas históricas da cultura popular. In: COHN, Gabriel (org.) Comunicação e Indústria Cultural. 2. ed. São Paulo: Companhia Editora Nacional, 1975. pp. 296-311.

KUPER, Adam. Cultura. A visão dos antropólogos. Bauru: EDUSC, 2002.

MICELI, Sérgio. Teoria e prática da política cultural oficial no Brasil. Revista de Administração de Empresas. Rio de Janeiro, 24(1): pp. 27-31. jan./mar. 1984.

MINISTÉRIO DA CULTURA e CÂMARA FEDERAL. Plano Nacional de Cultura. 2008.

NEVES, Sandro Campos. O Plano Nacional de Cultura e os índios: dilemas e tradições políticas na articulação de um pensamento sobre povos e culturas indígenas no Brasil. Políticas Culturais em Revista 2 (1), pp.91-110, 2008 www.politicasculturaisemrevista.ufba.br.

OLIVEN, Ruben George. Patrimônio Intangível: considerações iniciais. In: ABREU, Regina e CHAGAS, Mário (org). Memória e Patrimônio: Ensaios Contemporâneos. 2. ed. Rio de Janeiro: Lamparina, 2009.

OOSTERBEEK, Luiz Miguel e SCHEUNEMANN, Inguelore. Falsas contradições entre crescimento e desenvolvimento. In: Custo Brasil. Soluções para o desenvolvimento. Ano 5: no25. pp. 28-31, : fev./mar. 2010.

RUBIM, Antonio Albino Canelas. Plano Nacional de Cultura em debate. In: Políticas Culturais em Revista, 2 (1), pp.59-72, 2008 www.politicasculturaisemrevista.ufba.br.

SAHLINS, Marshall. O "pessimismo sentimental" e a experiência etnográfica: por que a cultura não é um "objeto" em via de extinção (parte I). Mana vol.3. n.1, Rio de Janeiro, 1997.

TAMASO, Isabela. A Expansão do Patrimônio: novos olhares sobre velhos objetos, outros desafios... In: Sociedade e Cultura, UFG, v. 8, n. 2, pp. 13-36, 2005. 